\title{
Review Article \\ Uterine Fibroids: Pathogenesis and Interactions with Endometrium and Endomyometrial Junction
}

\author{
Andrea Ciavattini, ${ }^{1}$ Jacopo Di Giuseppe, ${ }^{1}$ Piergiorgio Stortoni, ${ }^{1}$ Nina Montik, \\ Stefano R. Giannubilo, ${ }^{1}$ Pietro Litta, ${ }^{2}$ Md. Soriful Islam, ${ }^{3}$ Andrea L. Tranquilli, ${ }^{1}$ \\ Fernando M. Reis, ${ }^{4}$ and Pasquapina Ciarmela ${ }^{3}$
}

${ }^{1}$ Woman's Health Sciences Department, Faculty of Medicine, Polytechnic University of Marche, Via Corridoni 11, 60123 Ancona, Italy

${ }^{2}$ Department of Gynaecological Sciences and Human Reproduction, University of Padova, Via Giustiniani 3, 35128 Padova, Italy

${ }^{3}$ Department of Experimental and Clinical Medicine, Faculty of Medicine, Polytechnic University of Marche, Via Tronto 10/a, 60126 Ancona, Italy

${ }^{4}$ Department of Obstetrics and Gynecology, Federal University of Minas Gerais and National Institute of

Hormones and Women's Health, 30130-100 Belo Horizonte, MG, Brazil

Correspondence should be addressed to Andrea Ciavattini; ciavattini.a@libero.it

Received 28 February 2013; Revised 10 June 2013; Accepted 13 August 2013

Academic Editor: Hilary Critchley

Copyright (C) 2013 Andrea Ciavattini et al. This is an open access article distributed under the Creative Commons Attribution License, which permits unrestricted use, distribution, and reproduction in any medium, provided the original work is properly cited.

\begin{abstract}
Uterine leiomyomas (fibroids or myomas) are benign tumors of uterus and clinically apparent in a large part of reproductive aged women. Clinically, they present with a variety of symptoms: excessive menstrual bleeding, dysmenorrhoea and intermenstrual bleeding, chronic pelvic pain, and pressure symptoms such as a sensation of bloatedness, increased urinary frequency, and bowel disturbance. In addition, they may compromise reproductive functions, possibly contributing to subfertility, early pregnancy loss, and later pregnancy complications. Despite the prevalence of this condition, myoma research is underfunded compared to other nonmalignant diseases. To date, several pathogenetic factors such as genetics, microRNA, steroids, growth factors, cytokines, chemokines, and extracellular matrix components have been implicated in the development and growth of leiomyoma. This paper summarizes the available literature regarding the ultimate relative knowledge on pathogenesis of uterine fibroids and their interactions with endometrium and subendometrial myometrium.
\end{abstract}

\section{Introduction}

Leiomyomas are benign uterine tumors of unknown aetiology. These kinds of lesions seem to arise from myometrial transformation as a result of specific physiological and pathological conditions. The majority of these monoclonal estrogen-dependent uterine neoformations [1] afflict mostly women during reproductive age, and $80 \%$ of them suffer from this during their whole lifetime [2]. In the past, most women with fibroids remained undiagnosed, because they were asymptomatic. Analyses based on clinical diagnosis or diagnostic tests underestimate the true incidence; in fact, they take only into account symptomatic patients.
Cramer and Patel [3] estimated the prevalence of uterine fibroids based on clinical assessment at $33 \%$, ultrasound scan at $50 \%$, and histological examination of hysterectomy specimens at $77 \%$. The reported frequency of the disease varies widely due to differences in study design. In fact, to determine the exact prevalence of fibroids, a correct clinical research should apply ultrasound scanning in a randomly sampled population [4].

Nowadays, conflicting data about the pathogenesis of leiomyomas coexist in the literature. The development of uterine myomas can be linked to predisposing risk factors, initiators and genetic mechanisms, promoters, and effectors. The aim of this work is to discuss the latest knowledge on the 
pathogenesis of uterine fibroids and their interactions with the endometrium and subendometrial myometrium.

\section{Pathogenesis of Uterine Leiomyoma}

2.1. Risk Factors. Even if many risk factors suggested by epidemiologic studies have linked uterine leiomyomas to the effects of estrogens and progesterone levels and their metabolism, other mechanisms may be involved in fibroids pathogenesis. In fact, recently, Peddada et al. [5] have questioned the exact role of female hormones (estrogens and progesterone) in the development and growth of uterine fibroids. The authors measured the growth of fibroids in black and white women with clinically relevant fibroids using MRI technology; they demonstrated that fibroids within the same woman often have different growth rates despite having a similar hormonal milieu. In the same patients, fibroids were found to vary in size, regress, or remain stable. Each tumor appeared to have its own intrinsic growth rate, and fibroid growth appeared not to be influenced by tumor characteristics such as size and location. This study encouraged new research directions, consistent with studies showing that fibroids are monoclonal in origin with variable molecular characteristics [6-9]. Wei et al. [7] also found ethnic differences in expression of the dysregulated proteins in uterine leiomyomata. Tumor size has been related to variation in molecular markers $[6-8,10]$, and it has been assumed that the molecular differences reflect differences in tumor growth rates. Moreover, molecular markers also may differ between tumors from blacks and whites [7, 10]. It has been generally accepted that myomas are more prevalent in blacks than in Caucasian and Hispanic populations [11, 12]. Although the cause of the higher prevalence among black women is unclear, differences in circulating estrogen levels have been found [13]. It is still unclear [14] whether these ethnical differences are genetic or due to known variations in hormonal metabolism, diet, or environmental factors. Recently, some authors reported a statistically significant inverse correlation between serum 25-(OH) Vit D levels and fibroid prevalence in black subjects $[15,16]$. Leppert et al. reported that the pathogenesis of fibroids seems to involve a positive feedback loop between extracellular matrix production and cell proliferation, and vitamin $\mathrm{D}$ might act to block the positive feedback [17]. It is also interesting that myomas and keloids, both more common in black women, have similar gene characteristics. Furthermore, it is well known that family history could represent a strong predisposing factor; the first-degree relatives of affected women have a 2.5 times increased risk of developing fibroids $[18,19]$. However, as recently reported from Saldana et al., such bias would invalidate self-reported family history as a predictor of fibroid risk [20].

Several studies $[13,14,18,19]$ reported a rapid increase of fibroid incidence after the age of 30 . This could be the result of time-related hormonal changes or an enhanced symptomatology from already existing fibroids. Furthermore, the high incidence of fibroids in the perimenopausal period could be responsible for increasing gynecologic surgery rates in women who have completed the childbearing period.
A study found that the risk of myomas increased $21 \%$ with each $10 \mathrm{~kg}$ increase in body weight and with increasing body mass index [21]. Shikora et al. reported similar results in women with greater than $30 \%$ body fat [22]. The adipose tissue converts adrenal and ovarian androgens into estrogens, whereas several mechanisms associated with obesity lead to decreased synthesis of sex hormone binding globulin. Consequently, the increase of biologically available estrogens could be responsible for increasing myoma prevalence and/or growth in overweight and obese women. Furthermore, Nair and Al-Hendy evaluated the association between obesityrelated chronic inflammation and initiation, as well as the progression of uterine leiomyoma by using an in vitro model with representative cell lines of adipocytes and human uterine leiomyoma cells. They demonstrated that coculture of adipocytes and uterine leiomyoma cells results in an increased proliferation of leiomyoma cells, and they have also demonstrated that TNF- $\alpha$ treatment increases human uterine leiomyoma cells proliferation in a concentration-dependent manner [23].

It is not clear whether diet habits, such as consuming red meat, ham, green vegetables, or fiber, could influence the growth of myomas. It is also difficult to analyze the specific effects of physical exercise on the development of uterine myomas, as only a few observational studies have addressed this aspect so far $[24,25]$.

Several studies have revealed that smoking may reduce the incidence of myomas; nicotine inhibits aromatase and reduces the conversion of androgens to estrone. Smoking also exerts a powerful inducing effect on the 2-hydroxylation pathway of estradiol metabolism, which is likely to lead to decreased bioavailability at estrogen target tissues [26-28].

An early menarche, before the age of 10 , has been found to be a risk factor for uterine myomas, while a menarche over the age of 16 seems to decrease the same risk [29]. Some studies stressed that a lower incidence and a reduced number of clinically apparent myomas are linked to increased parity [3032]. This could be due to a remodeling process of the extracellular matrix (ECM) and a specific expression of receptors for peptide and steroids hormones induced by pregnancy and parturition.

Postmenopausal hormone therapy seems not to be responsible for any important stimulus to fibroid growth [33]. Likewise, conflicting data coexist about the relationship between oral contraceptives (OC) and the growth of leiomyomas. This could be related to the differing content of estrogens and the type of progesterone in each specific OC preparation [34].

Several theories about the initiators of fibroids have been proposed. Rein [35] stated that increased levels of estrogens and progesterone could result in an augmentation of mitotic rate that could be responsible for somatic mutation. Richards and Tiltman found increased concentration of receptors for estrogens (ER) in certain regions of the nonneoplastic myometrium of uterus myomatous [36]. Another interesting theory underlines that the pathogenesis might be similar to a response to injury [37]; ischemic damage could be linked to release of increased vasoconstrictive substances at the time of the menses. Smooth muscle cells of the myometrium could 
react to injury with the synthesis of extracellular fibrous matrix [38]. After vascular damage, basic fibroblast growth factors are overexpressed in leiomyomas $[39,40]$.

2.2. Genetic Mechanism Involved in Fibroids Etiology. Historically, uterine leiomyomata have not been considered a genetic disease. However much recent clinical evidence indicates that at least some myomata have a genetic etiology. Actually, cytogenetic surveys have found that about $40 \%$ of uterine fibroids are chromosomally altered and bear cytogenetic anomalies shared by several other types of tumors. For example, studies found translocations between chromosomes 12 and 14, trisomy 12, translocations between chromosomes 6 and 10, and deletions of chromosomes 3 and 7 [41].

The HMGA2 gene was found in translocation 12:14, the most common cytogenetic abnormality, that occurs in about $20 \%$ of chromosomally abnormal lesions. This gene encodes a high mobility group DNA binding protein and embryonic proliferation modulator [42]. The HMGA2 gene is expressed in uterine leiomyoma and in other human tissues with a proliferative phenotype, such as fetal tissues, lung, and kidney, but not in the normal myometrium [43]. Markowski et al. found that the antagonism of HMGA2 in vitro decreased leiomyoma cell proliferation [44].

Heritable cancer syndromes can be characterized by uterine leiomyomas such as hereditary leiomyomatosis and renal cell cancer (HLRCC). This syndrome predisposes patients to benign leiomyomas of skin and uterus and early-onset renal cell carcinoma. Fumarate hydratase (FH) is the gene implied; it encodes a Kreb's cycle enzyme responsible for conversion of fumarate to malate [45]. Alport syndrome is an X-linked progressive nephropathy associated with leiomyomas due to defect in COL4A5 and COL4A6 genes [46].

Cha and colleagues [47] genotyped 1607 individuals with uterine fibroids and identified 3 susceptibility loci associated with uterine fibroids. Chromosome 10q24.33 seems to have the best association with leiomyomas; the region was mapped to the $5^{\prime}$ region of the SLK gene encoding STE20-like kinase. STE20-like kinase has a role in myogenic differentiation, and, after activation by epithelial disruption, it is expressed in proliferating myoblasts. Another gene product located in the region is A-kinase anchor protein-13 (AKAP13), associated with cytoskeletal filaments. Related mutations could alter the regulation of extracellular matrix deposition and, consequently, of the fibrotic phenotype of the leiomyoma [48].

Recent studies described that $70 \%$ of fibroids contained a series of mutations in a transcriptional regulator complex subunit 12 (MED12) [49, 50]. Pérot et al. reported that MED12 is frequently mutated in typical leiomyomas $(66.6 \%)$ and also that mutations are not restricted to benign tumors since highly aggressive leiomyosarcomas were also mutated. However, no mutations were detected in nonuterine leiomyosarcomas; so Pérot et al. affirmed that MED12 seems to be specific to uterine smooth muscle tumors [51]. Previously, it has been shown that MED12 is implicated in transcription activation of Wnt target genes by interacting with $\beta$-catenin $[52,53]$. However a recent study combining mRNA and miRNA differential expression between fibroids and myometrium has observed a downregulation of the Wnt pathway and an upregulation of the focal adhesion pathway in leiomyomas [54]. The $\beta$-catenin immunohistochemistry data tends to indicate that the canonical Wnt pathway is not implicated in fibroids development, since $\beta$-catenin, when expressed, is located at the membrane in mutated cases; a localization which has been demonstrated to be indicative of a low transactivation activity $[51,55,56]$.

The same authors [51] concluded that the Wnt $/ \beta$-catenin pathway does not seem constitutively activated in MED12 mutated tumors, and they hypothesize that if MED12 mutations play a role in uterine tumor development, it is probably not through Wnt target genes activation in association with $\beta$-catenin.

\subsection{Role of Mechanical Transduction and Extracellular Matrix.} Research for the pathogenesis of fibroids and abnormal extracellular matrix (ECM) led to the analysis of a growth factor with profibrotic activity, transforming growth factor $\beta$ (TGF$\beta$ ) $[17,57]$. The $\beta 3$ subunit of TGF- $\beta 3$ and its signal mediators are overexpressed in leiomyomas compared to normal myometrium [58]. Furthermore, the mRNA expression of multiple ECM genes in uterine leiomyomas is decreased when the TGF- $\beta$ pathway is downregulated [59].

Norian et al. have examined the role of ECM, opening new directions of research. They reported that mechanical signals are transmitted from the ECM scaffold via transmembrane receptors to the internal cytoskeleton in order to maintain an isometric state. Transmembrane receptors respond to stretch, fluid shear stress, elevated hydrostatic pressure, and increased osmotic forces. In this way, myometrial cells react to, and may be protected from, external loads by the mechanical properties of the surrounding matrix through secretion of ECM. The authors [60] have demonstrated that the ECM microenvironment of leiomyoma cells is characterized by increased mechanical stress. They extended the results of their previous study [48] showing that the viscoelastic properties of the ECM contribute substantially to the increased tissue stiffness of leiomyoma. They hypothesized that since the viscoelastic properties of the ECM are complex, it is possible that the interstitial fluid may alter the repulsive forces of the glycosaminoglycans allowing them to collapse or inflate. So the authors [60] suggested that the mechanical properties of leiomyoma are a key feature of these tumors and may contribute to their growth.

2.4. MicroRNA. Epigenetic changes have also been implicated in leiomyoma formation. Studies directed at identifying epigenetic abnormalities in fibroids demonstrated abnormally hypomethylated ER- $\alpha$ [61]. Follow-up studies demonstrated globally abnormal genomic methylation in leiomyomas compared to myometrium [62], implicating possible epigenetic contributions to genetic susceptibility of leiomyoma development. Knowledge regarding the molecular causes of uterine leiomyomas is in its infancy. Early studies suggest common mutations that correlate with the development of leiomyomas. MicroRNAs (miRNAs) are a novel class of small nonprotein coding RNAs which regulate a high number of biological processes by targeting mRNAs for cleavage 
or translational repression $[63,64]$. Several miRNAs such as let7, miR-21, miR-93, miR-106b, and miR-200 are significantly dysregulated in uterine leiomyoma compared to those in normal myometrium $[10,65]$. Further research will need to identify specific genes responsible for the development of leiomyomas that can be directly targeted as preventive therapy. Additional efforts need to be directed at investigating specific inhibitors of disrupted pathways involved in the leiomyoma growth in susceptible patients. The wide spectrum of clinical and genetic heterogeneity of uterine leiomyomas underscores the importance of continued investigation to determine the various molecular etiologies that result in leiomyoma development.

2.5. Estrogens. Uterine leiomyoma growth is strictly related to estrogens and their receptors. Several studies found that mRNA and protein expression levels as well as the content of ER- $\alpha$ and ER- $\beta$ are higher in leiomyoma compared to those in normal myometrium $[66,67]$. According to their hypothesis, estrogens may exert their growth-stimulatory effects on leiomyomas intermediated by cytokines, growth factors, or apoptosis factors [68]. Ishikawa et al. [69] suggested that estrogens can maintain progesterone receptor (PR) levels, and thus progesterone through its receptor may promote leiomyoma growth. Furthermore, other authors suggested that estrogens may stimulate leiomyoma growth partially by suppressing normal p53 functions [70].

Estrogens are able to regulate the expression of growth factors by activating some signaling pathways. Estrogens upregulate platelet-derived growth factor (PDGF) expression [71] in leiomyoma cells, while they downregulate activin and myostatin [72] in human myometrial explants. In addition, estrogens also downregulate epidermal growth factor (EGF) expression but upregulate the expression of EGF-R in both myometrium and leiomyoma cells [73, 74]. These estrogen actions are accomplished through the rapid activation of different kinds of kinases; some of them [75] result to be increased in both immortalized uterine smooth muscle and leiomyoma cell lines under estrogen stimulation. In addition, Park and colleagues reported that estrogens may also stimulate the proliferation of leiomyoma cells by activating ATPsensitive potassium channels [76].

2.6. Progesterone. Progesterone interacts with its receptors PR-A and PR-B [77] playing a key role in myometrial and leiomyoma biologies $[78,79]$. Several studies have stressed that PR content and mRNA levels are higher in leiomyoma than those in normal myometrium [80-84], and, in particular, Fujimoto et al. [85] described the relative overexpression of PR-B mRNA in the surface of leiomyoma.

Leiomyoma growth is influenced by progesterone interaction with some growth factors; it upregulates the EGF (mitogenic) [73] and transforming growth factor- (TGF-) $\beta 3$ (bimodal action) [86] expression. On one hand, progesterone seems to downregulate IGF-I expression through PRB, while PRA appears to inhibit this function [84].

Some authors hypothesized that progesterone could stimulate leiomyoma cell growth and survival through upregulating B-cell lymphoma- (Bcl-)2 protein expression and downregulating tumour necrosis factor- (TNF-) $\alpha$ expression [87, 88]. Recently, Luo et al. [89] defined L-type amino acid transporter 2 (LAT2) as a novel PR target gene. Progesterone significantly induces LAT2 mRNA levels, which is blocked by cotreatment with the PR antagonist mifepristone. In the same way, Yin et al. found eighteen novel PR-binding sites, one of which is Krüppel-like transcription factor 11 (KLF11) which is minimally downregulated by progesterone [90].

2.7. Growth Factors. Several growth factors, such as vascular endothelial growth factor (VEGF), EGF, heparin binding epidermal growth factor (HB-EGF), PDGF, IGF, TGF- $\alpha$, TGF- $\beta$, acidic fibroblast growth factor (aFGF), and basic fibroblast growth factor (bFGF), and their respective receptors have been demonstrated to play a role in leiomyoma growth [91, 92]. In particular, bFGF [93] and VEGF [94] have also been shown to promote angiogenesis in leiomyoma. EGF and PDGF seem to increase DNA synthesis and polyploidization in leiomyoma cells through transient activation of kinase pathways [95-97]. PDGF also modulates the rate of cell proliferation in myometrium and leiomyoma cells [98-100].

TGF- $\beta 3$ induces elevated expression of ECM-related genes and decreases the expression of ECM degradationrelated genes [101]. TGF- $\beta$ can also activate kinase pathways (MAPK/ERK/Smad) and thereby modulate the expression of different types of genes influencing the leiomyoma growth and regression [102]. Similarly, IGF may increase cellular proliferation in uterine leiomyoma cells through activation of the MAPK pathway [103] and thus play a crucial role in leiomyoma cell growth, by upregulation of $\mathrm{Bcl}-2$ protein expression in leiomyoma cells [104].

Recently, activin and myostatin have been identified in the myometrium and in leiomyoma, and Ciarmela et al. [105, 106] have hypothesized that activin-A and myostatin could regulate myometrial cell proliferation, describing higher expression levels of this molecule in leiomyoma compared to that in adjacent myometrium samples. Additionally, several less studied factors such as parathyroid hormone-related peptide $[107,108]$, prolactin $[109,110]$, endothelin-1 $[111,112]$, human chorionic gonadotropin [113], and pituitary tumortransforming growth factor-1 [114] have also been implicated or hypothesized in myometrial biology.

2.8. Cytokines and Chemokines. Many cytokines, including tumor necrosis factor- $\alpha$ [87], erythropoietin [115], interleukin- (IL-)1 [116], and IL-6 [117], have been implicated in development of uterine leiomyoma. Even chemokines and their receptors (MIP- $1 \alpha$, MIP- $1 \beta$, RANTES, eotaxin, eotaxin-2, IL-8, CCR1, CCR3, CCR5, CXCR1, and CXCR2 mRNA) have been shown to be mediators of the above mentioned process [118-120]. Sozen et al. [121] found that MCP-1 mRNA levels are higher in myometrium compared to leiomyoma and that estrogens and progestins decrease MCP-1 protein production, suggesting that MCP-1 may have antineoplastic activity in leiomyoma. IL-8 and IL-8 receptors type A have been identified with the elevated expression in myometrium compared to leiomyoma [122]. Hatthachote and Gillespie [116] described that this chemokine also upregulates 
TGF- $\beta 1$ and TGF receptor expression in vitro in human term myometrium.

In experimental systems, increasing carcinogen exposure tends to increase the number of tumors and their degree of malignancy. Low carcinogen exposure tends to produce benign neoplasms, whereas high exposure tends to produce both malignancies and higher numbers of tumors $[3,123$, 124].

2.9. Extracellular Matrix Components. Extracellular disorganized matrix is a peculiar characteristic of fibroid growth, mainly consisting of collagen subtypes, fibronectin, and proteoglycans. Recently, a series of collagen subtypes, such as COL1A1, 4A2, 6A1, 6A2, 7A1, and 16A1, have been found expressed to a greater extent in leiomyoma cells compared to myometrial cells [125]. Leiomyomas and myometrium are characterized by variable expression of glycosaminoglycans and their protein bound forms, proteoglycans [126, 127]. Matrix metalloproteinases (MMPs) have also been implicated in leiomyoma remodeling. Bodner-Adler et al. [128] found that MMP-1 is expressed more in leiomyomas, while MMP-2 is less expressed. Alternatively, another work found MMP-1, MMP-2, MMP-3, and MMP-9 with higher activity of MMP2 in leiomyoma compared to myometrium [126]. Recently, Bogusiewicz et al. revealed increased MMP-2 activity in leiomyomas than in surrounding myometrium [129].

\section{Fibromatosis, Endometrium, and Endomyometrial Junction}

The advances in pathogenetic knowledge of fibroids and the introduction of magnetic resonance imaging led to the study of endomyometrial junction [130], the interface between cyclic endometrium and the myometrium, where important vascular and physiochemical phenomena seem to take place. Tocci et al. [131] proposed that the "endometrialsubendometrial myometrium unit disruption disease" should be considered as a new entity and distinguished from adenomyosis. This condition is expressed mainly by a pathological thickening or abnormality of the subendometrial myometrium, that is, the possible site of origin of submucosal and intramural fibroids. The study also reports on the influence of abnormal thickening or disruption on human fertility and outcome of assisted reproduction techniques. The mechanism underlying zonal myometrial differentiation is not known, but growing evidence suggests that ovarian hormone action may be mediated by cytokines and uterotonins locally released by the basal endometrial layer and endometrialmyometrial T-lymphocytes. Irregular thickening of the junctional zone due to inordinate proliferation of the inner myometrium, junctional zone hyperplasia, is a common MR finding in women suffering from menstrual dysfunction [132].

Nowadays, it is not well established how uterine fibroids could interfere with the endometrial environment and the subendometrial myometrium and vice versa. In these patients, the interaction between the endomyometrium and fibromatosis could have a role in influencing their fertility and the risk of miscarriage. The American Society for Reproductive Medicine has reported that uterine myomas are associated with infertility in 5-10\% of cases [133] and may be responsible for 2-3\% of infertility cases [134]. All confounding variables may be difficult to control when searching for the impact of fibroids on infertility, and there is no definitive association between reproductive dysfunction, miscarriage and fibroids.

Some studies [135-138] indicated that the uterine tissue is susceptible to fibrinogenesis, as seen in rare occasions in response to mechanical injury in women undergoing endometrial ablation and caesarean delivery and in women affected by Asherman's syndrome. In all these cases, in fact, there is an involvement of the subendometrial myometrium, an alteration of endometrial microvascular blood flow with endometrial atrophy and abnormal activation of cytokines and chemokines, which might have an important role in the pathogenesis of uterine leiomyomas and related symptoms. Frequent mucosal injury with stromal repair reactions may release growth factors that promote the high frequency and multiplicity of uterine leiomyomas [139].

A threefold increase in percentage of nuclear area was found in the junctional zone in comparison with the outer myometrium, reflecting an increase in both size and number of nuclei. No difference in distribution of common components of the extracellular space (collagen, laminin, and fibronectin) was found between the two layers [140].

It has been reported that myomectomy can increase the pregnancy rate for patients with infertility [141]. However, the mechanisms by which this occurs are not well understood. Many hypotheses have been suggested. First, fibroids could alter uterine cavity contour, through a mechanical distortion, or they could be responsible for an abnormal uterine contractility $[142,143]$. Moreover, local inflammation associated with the presence of fibroids may give rise to a hostile endometrial environment that impairs sperm transport and embryo implantation. Some authors $[144,145]$ reported that excessive concentrations of inflammatory cytokines could have negative effects on embryonic development and implantation. Inagaki et al. [146] demonstrated that uterine cavities containing fibroids or adenomyosis showed a state of excess inflammation, with upregulation of MMPs and inflammatory cytokines such as interleukin- 1 and TNF- $\alpha$. In particular, the levels of MMPs in the uterine cavity of women with leiomyoma and adenomyosis were significantly higher than those in women with a histologically normal uterus. Matsuzaki et al. [147] detected significantly lower expression levels of HOXA10 in patients with uterine leiomyoma. HOXA-10 is one of the best-recognized sequences of signaling events in implantation [148].

A study reported that HOXA10 and HOXA11 mRNA expression were significantly decreased in uteri with submucosals myomas compared to those in controls with normal uterine cavity and to uteri with intramural myomas [149]. Although intramural myomas were not associated with a significant change in these markers of endometrial receptivity, the same authors noted a trend toward decreased endometrial HOXA10 mRNA and stromal protein expression in the intramural myoma group compared to those in the control 
group. Sinclair et al. [150] evaluated the effect of leiomyoma on endometrial gene expression essential for implantation and haemostasis both in vivo and in primary endometrial stromal cells. They hypothesized that failure of blastocyst implantation in women with uterine leiomyomas is secondary to impaired BMP-2-mediated decidualization. BMP-2 is a growth factor that belongs to the TGF- $\beta$ superfamily. It regulates cell proliferation and differentiation. Conditional ablation of BMP-2 in murine endometrium results in complete infertility because BMP- $2^{\mathrm{d} / \mathrm{d}}$ mice are unable to form implantation sites and demonstrate a complete lack of decidual response [151].

The authors tested the hypothesis that TGF- $\beta 3$ may cause impaired decidualization in endometrial stromal cells by inducing BMP-2 resistance. They found a significant reduction in HOXA10 in leiomyoma-associated endometrial stromal treated with $\mathrm{rhTGF}-\beta 3$ supporting this hypothesis. TGF- $\beta 3$ downregulated BMP receptors. The significant reduction in BMPR gene expression in response to treatment with rhTGF- $\beta 3$ suggests that TGF- $\beta 3$ induces BMP-2 resistance by downregulation of the BMPRs. Persistently decreased receptor expression explains the continued lack of BMP-2 response of endometrial stromal cells in culture.

Morosova et al. [152] studied common polymorphisms of MMP genes in myometrial and endometrial hyperplasia. An accelerated leiomyoma growth correlated with higher frequency of the MMP-1 2G allele. MMP-1 2G was also associated with multinodular growth, and it also tended to increase in patients with adenomyosis, suggesting that the $2 \mathrm{G}$ (-1607)MMP-1 genotype may be a potential risk marker of myometrial and endometrial hyperplasia.

\section{Conclusions}

The etiopathology of uterine fibroid remains unclear, multifactorial, and enigmatic. Classic studies showed steroid dependence of myomas for growth and development. The genetic background seems to play an important role, with cytogenetic anomalies observed in about $40 \%$ of uterine fibroids. Abnormal ECM expression, increased growth factors, cytokines and chemokines concentrations, and an extracellular disorganized matrix have been implicated in development and growth of uterine leiomyomas.

However, clinical aspects are related prevalently to the number, volume, and intrauterine localization of nodes. In particular, submucosal nodes are associated with important clinical manifestations, and it is still not well established how uterine fibroids could interfere with the endometrial environment and the subendometrial myometrium and vice versa. It has been proposed that the "endometrial-subendometrial myometrium unit disruption disease" should be considered as a new entity and distinguished from adenomyosis [131]. This condition is expressed by a pathological thickening or abnormality of the subendometrial myometrium, that is, the possible site of origin of submucosal and intramural fibroids. Recent findings suggested that myomatosis and adenomyosis share some pathogenetic features like a state of excess inflammation, increased endothelial nitric oxide synthesis with upregulation of MMP, and inflammatory cytokines such as interleukin-1 and TNF- $\alpha$.

Endomyometrial junction disruption might play a crucial role on fibroid-related infertility, uterine bleeding, and growth of submucosal and intramural myomas.

Nowadays, there is a clear trend to delay the time of pregnancy, and the clinical and the social impact of uterine fibromatosis is growing and requires future studies to clarify the etiopathogenesis and elaborate new and effective therapies for this condition.

\section{Authors' Contribution}

Fernando M. Reis and Pasquapina Ciarmela contributed equally to this paper.

\section{Acknowledgment}

Publication is supported by Conselho Nacional de Desenvolvimento Científico e Tecnológico (CNPq, 310 Grant no. 479532/2012-5), Brazil.

\section{References}

[1] W. Bowden, J. Skorupski, E. Kovanci, and A. Rajkovic, "Detection of novel copy number variants in uterine leiomyomas using high-resolution SNP arrays,' Molecular Human Reproduction, vol. 15, no. 9, pp. 563-568, 2009.

[2] S. K. Laughlin, J. C. Schroeder, and D. D. Baird, "New directions in the epidemiology of uterine fibroids," Seminars in Reproductive Medicine, vol. 28, no. 3, pp. 204-217, 2010.

[3] S. F. Cramer and A. Patel, "The frequency of uterine leiomyomas," American Journal of Clinical Pathology, vol. 94, no. 4, pp. 435-438, 1990.

[4] M. Payson, P. Leppert, and J. Segars, "Epidemiology of myomas," Obstetrics and Gynecology Clinics of North America, vol. 33, no. 1, pp. 1-11, 2006.

[5] S. D. Peddada, S. K. Laughlin, K. Miner et al., "Growth of uterine leiomyomata among premenopausal black and white women," Proceedings of the National Academy of Sciences of the United States of America, vol. 105, no. 50, pp. 19887-19892, 2008.

[6] M. K. Lobel, P. Somasundaram, and C. C. Morton, "The genetic heterogeneity of uterine leiomyomata," Obstetrics and Gynecology Clinics of North America, vol. 33, no. 1, pp. 13-39, 2006.

[7] J. Wei, L. Chiriboga, A. A. Arslan, J. Melamed, H. Yee, and K. Mittal, "Ethnic differences in expression of the dysregulated proteins in uterine leiomyomata," Human Reproduction, vol. 21, no. 1, pp. 57-67, 2006.

[8] J. Wei, L. Chiriboga, and K. Mittal, "Expression profile of the tumorigenic factors associated with tumor size and sex steroid hormone status in uterine leiomyomata," Fertility and Sterility, vol. 84, no. 2, pp. 474-484, 2005.

[9] M. Wolańska and E. Bańkowski, “Transforming growth factor $\beta$ and platelet-derived growth factor in human myometrium and in uterine leiomyomas at various stages of tumour growth," European Journal of Obstetrics Gynecology and Reproductive Biology, vol. 130, no. 2, pp. 238-244, 2007.

[10] T. Wang, X. Zhang, L. Obijuru et al., "A micro-RNA signature associated with race, tumor size, and target gene activity in 
human uterine leiomyomas," Genes Chromosomes and Cancer, vol. 46, no. 4, pp. 336-347, 2007.

[11] L. M. Marshall, D. Spiegelman, R. L. Barbieri et al., "Variation in the incidence of uterine leiomyoma among premenopausal women by age and race," Obstetrics and Gynecology, vol. 90, no. 6, pp. 967-973, 1997.

[12] K. H. Kjerulff, P. Langenberg, J. D. Seidman, P. D. Stolley, and G. M. Guzinski, "Uterine leiomyomas: racial differences in severity, symptoms and age at diagnosis," Journal of Reproductive Medicine for the Obstetrician and Gynecologist, vol. 41, no. 7, pp. 483-490, 1996.

[13] G. P. Flake, J. Andersen, and D. Dixon, "Etiology and pathogenesis of uterine leiomyomas: a review," Environmental Health Perspectives, vol. 111, no. 8, pp. 1037-1054, 2003.

[14] W. H. Parker, "Etiology, symptomatology, and diagnosis of uterine myomas," Fertility and Sterility, vol. 87, no. 4, pp. 725736, 2007.

[15] D. D. Baird, M. C. Hill, J. M. Schectman, and B. W. Hollis, "Vitamin D and the risk of uterine fibroids," Epidemiology, vol. 24, pp. 447-453, 2013.

[16] M. Sabry, S. K. Halder, A. S. Allah, E. Roshdy, V. Rajaratnam, and A. Al-Hendy, "Serum vitamin D3 level inversely correlates with uterine fibroid volume in different ethnic groups: a crosssectional observational study,' International Journal of Women's Health, vol. 5, pp. 93-100, 2013.

[17] P. C. Leppert, W. H. Catherino, and J. H. Segars, "A new hypothesis about the origin of uterine fibroids based on gene expression profiling with microarrays," American Journal of Obstetrics and Gynecology, vol. 195, no. 2, pp. 415-420, 2006.

[18] S. M. Schwartz, L. M. Marshall, and D. D. Baird, "Epidemiologic contributions to understanding the etiology of uterine leiomyomata," Environmental Health Perspectives, vol. 108, supplement 5, pp. 821-827, 2000.

[19] E. M. Vikhlyaeva, "Familial predisposition to uterine leiomyomas," International Journal of Gynecology and Obstetrics, vol. 51, no. 2, pp. 127-131, 1995.

[20] T. M. Saldana, M. Moshesh, and D. D. Baird, "Self-reported family history of leiomyoma: not a reliable marker of high risk," Annals of Epidemiology, vol. 23, no. 5, pp. 286-290, 2013.

[21] R. K. Ross, M. C. Pike, and M. P. Vessey, "Risk factors for uterine fibroids: reduced risk associated with oral contraceptives," The British Medical Journal, vol. 293, no. 6543, pp. 359-362, 1986.

[22] S. A. Shikora, J. M. Niloff, B. R. Bistrian, R. A. Forse, and G. L. Blackburn, "Relationship between obesity and uterine leiomyomata," Nutrition, vol. 7, no. 4, pp. 251-255, 1991.

[23] S. Nair and A. Al-Hendy, "Adipocytes enhance the proliferation of human leiomyoma cells via TNF- $\alpha$ proinflammatory cytokine," Reproductive Sciences, vol. 18, no. 12, pp. 1186-1192, 2011.

[24] F. Chiaffarino, F. Parazzini, C. La Vecchia, L. Chatenoud, E. Di Cintio, and S. Marsico, "Diet and uterine myomas," Obstetrics and Gynecology, vol. 94, no. 3, pp. 395-398, 1999.

[25] G. Wyshak, R. E. Frisch, and N. L. Albright, "Lower prevalence of benign diseases of the breast and benign tumours of the reproductive system among former college athletes compared to non-athletes," British Journal of Cancer, vol. 54, no. 5, pp. 841845, 1986.

[26] R. L. Barbieri, P. M. McShane, and K. J. Ryan, "Constituents of cigarette smoke inhibit human granulosa cell aromatase," Fertility and Sterility, vol. 46, no. 2, pp. 232-236, 1986.

[27] J. J. Michnovicz, R. J. Hershcopf, and H. Naganuma, "Increased 2-hydroxylation of estradiol as a possible mechanism for the anti-estrogenic effect of cigarette smoking," The New England Journal of Medicine, vol. 315, no. 21, pp. 1305-1309, 1986.

[28] M. Daniel, A. D. Martin, and D. T. Drinkwater, "Cigarette smoking, steroid hormones, and bone mineral density in young women," Calcified Tissue International, vol. 50, no. 4, pp. 300305, 1992.

[29] A. J. Tiltman, "The effect of progestins on the mitotic activity of uterine fibromyomas," International Journal of Gynecological Pathology, vol. 4, no. 2, pp. 89-96, 1985.

[30] F. Parazzini, E. Negri, C. La Vecchia, L. Chatenoud, E. Ricci, and P. Guarnerio, "Reproductive factors and risk of uterine fibroids," Epidemiology, vol. 7, no. 4, pp. 440-442, 1996.

[31] P. Lumbiganon, S. Rugpao, S. Phandhu-fung, M. Laopaiboon, N. Vudhikamraksa, and Y. Werawatakul, "Protective effect of depot-medroxyprogesterone acetate on surgically treated uterine leiomyomas: a multicentre case-control study, British Journal of Obstetrics and Gynaecology, vol. 103, no. 9, pp. 909914, 1996.

[32] D. D. Baird and D. B. Dunson, "Why is parity protective for uterine fibroids?” Epidemiology, vol. 14, no. 2, pp. 247-250, 2003.

[33] S. Palomba, T. Sena, M. Morelli, R. Noia, F. Zullo, and P. Mastrantonio, "Effect of different doses of progestin on uterine leiomyomas in postmenopausal women," European Journal of Obstetrics Gynecology and Reproductive Biology, vol. 102, no. 2, pp. 199-201, 2002.

[34] D. W. Cramer, "Epidemiology of myomas," Seminars in Reproductive Endocrinology, vol. 10, no. 4, pp. 320-324, 1992.

[35] M. S. Rein, "Advances in uterine leiomyoma research: the progesterone hypothesis," Environmental Health Perspectives, vol. 108, no. 5, pp. 791-793, 2000.

[36] P. A. Richards and A. J. Tiltman, "Anatomical variation of the oestrogen receptor in the non-neoplastic myometrium of fibromyomatous uteri," Virchows Archiv, vol. 428, no. 6, pp. 347-351, 1996.

[37] E. A. Stewart and R. A. Nowak, "Leiomyoma-related bleeding: a classic hypothesis updated for the molecular era," Human Reproduction Update, vol. 2, no. 4, pp. 295-306, 1996.

[38] D. Dixon, G. P. Flake, A. B. Moore et al., "Cell proliferation and apoptosis in human uterine leiomyomas and myometria," Virchows Archiv, vol. 441, no. 1, pp. 53-62, 2002.

[39] V. Lindner and M. A. Reidy, "Proliferation of smooth muscle cells after vascular injury is inhibited by an antibody against basic fibroblast growth factor," Proceedings of the National Academy of Sciences of the United States of America, vol. 88, no. 9, pp. 3739-3743, 1991.

[40] R. S. Mangrulkar, M. Ono, M. Ishikawa, S. Takashima, M. Klagsbrun, and R. A. Nowak, "Isolation and characterization of heparin-binding growth factors in human leiomyomas and normal myometrium," Biology of Reproduction, vol. 53, no. 3, pp. 636-646, 1995.

[41] K. L. Gross and C. C. Morton, "Genetics and the development of fibroids," Clinical Obstetrics and Gynecology, vol. 44, pp. 335349, 2001.

[42] J. C. Hodge, K. T. Cuenco, K. L. Huyck et al., "Uterine leiomyomata and decreased height: a common HMGA2 predisposition allele," Human Genetics, vol. 125, no. 3, pp. 257-263, 2009.

[43] G. J. Gattas, B. J. Quade, R. A. Nowak, and C. C. Morton, "HMGIC expression in human adult and fetal tissues and in uterine leiomyomata," Genes, Chromosomes and Cancer, vol. 25, pp. 316-322, 1999. 
[44] D. N. Markowski, B. M. Helmke, G. Belge et al., "HMGA2 and p14Arf: major roles in cellular senescence of fibroids and therapeutic implications," Anticancer Research, vol. 31, no. 3, pp. 753-761, 2011.

[45] S. Sudarshan, P. A. Pinto, L. Neckers, and W. M. Linehan, "Mechanisms of disease: hereditary leiomyomatosis and renal cell cancer-a distinct form of hereditary kidney cancer," Nature Clinical Practice Urology, vol. 4, no. 2, pp. 104-110, 2007.

[46] V. Uliana, E. Marcocci, M. Mucciolo et al., "Alport syndrome and leiomyomatosis: the first deletion extending beyond COL4A6 intron 2," Pediatric Nephrology, vol. 26, no. 5, pp. 717724, 2011.

[47] P. Cha, A. Takahashi, N. Hosono et al., "A genome-wide association study identifies three loci associated with susceptibility to uterine fibroids," Nature Genetics, vol. 43, no. 5, pp. 447-451, 2011.

[48] R. Rogers, J. Norian, M. Malik et al., "Mechanical homeostasis is altered in uterine leiomyoma," American Journal of Obstetrics and Gynecology, vol. 198, no. 4, pp. 474.el-474.el1, 2008.

[49] N. Mäkinen, M. Mehine, J. Tolvanen et al., "MED12, the mediator complex subunit 12 gene, is mutated at high frequency in uterine leiomyomas," Science, vol. 334, no. 6053, pp. 252-255, 2011.

[50] E. M. Je, M. R. Kim, K. O. Min, N. J. Yoo, and S. H. Lee, "Mutational analysis of MED12 exon 2 in uterine leiomyoma and other common tumors," International Journal of Cancer, vol. 131, no. 6, pp. E1044-E1047, 2012.

[51] G. Pérot, S. Croce, A. Ribeiro et al., "MED12 alterations in both human benign and malignant uterine soft tissue tumors," PLoS One, vol. 7, no. 6, Article ID e40015, 2012.

[52] S. Kim, X. Xu, A. Hecht, and T. G. Boyer, "Mediator is a transducer of Wnt/ $\beta$-catenin signaling," The Journal of Biological Chemistry, vol. 281, no. 20, pp. 14066-14075, 2006.

[53] P. P. Rocha, M. Scholze, W. Bleiß, and H. Schrewe, "Med12 is essential for early mouse development and for canonical Wnt and Wnt/PCP signaling," Development, vol. 137, no. 16, pp. 27232731, 2010.

[54] J. Zavadil, H. Ye, Z. Liu et al., "Profiling and functional analyses of microRNAs and their target gene products in human uterine leiomyomas," PLoS ONE, vol. 5, no. 8, Article ID e12362, 2010.

[55] S. Lin, W. Xia, J. C. Wang et al., " $\beta$-catenin, a novel prognostic marker for breast cancer: its roles in cyclin D1 expression and cancer progression," Proceedings of the National Academy of Sciences of the United States of America, vol. 97, no. 8, pp. 42624266, 2000.

[56] Q. Qiao, M. Ramadani, S. Gansauge et al., "Reduced membranous and ectopic cytoplasmic expression of beta-catenin correlate with cyclin D1 overexpression and poor prognosis in pancreatic cancer," International Journal of Cancer, vol. 95, pp. 194-197, 2001.

[57] E. A. Kogan, V. E. Ignatova, T. N. Rukhadze, E. A. Kudrina, and A. I. Ischenko, "A role of growth factors in development of various histological types of uterine leiomyoma," Arkhiv Patologii, vol. 67, no. 3, pp. 34-38, 2005.

[58] J. M. Norian, M. Malik, C. Y. Parker et al., “Transforming Growth Factor $\beta 3$ regulates the versican variants in the extracellular matrix-rich uterine leiomyomas," Reproductive Sciences, vol. 16, no. 12, pp. 1153-1164, 2009.

[59] M. Malik, J. Webb, and W. H. Catherino, "Retinoic acid treatment of human leiomyoma cells transformed the cell phenotype to one strongly resembling myometrial cells," Clinical Endocrinology, vol. 69, no. 3, pp. 462-470, 2008.
[60] J. M. Norian, C. M. Owen, J. Taboas et al., "Characterization of tissue biomechanics and mechanical signaling in uterine leiomyoma," Matrix Biology, vol. 31, no. 1, pp. 57-65, 2012.

[61] H. Asada, Y. Yamagata, T. Taketani et al., "Potential link between estrogen receptor- $\alpha$ gene hypomethylation and uterine fibroid formation," Molecular Human Reproduction, vol. 14, no. 9, pp. 539-545, 2008.

[62] Y. Yamagata, R. Maekawa, H. Asada et al., "Aberrant DNA methylation status in human uterine leiomyoma," Molecular Human Reproduction, vol. 15, no. 4, pp. 259-267, 2009.

[63] D. P. Bartel, "MicroRNAs: genomics, biogenesis, mechanism, and function," Cell, vol. 116, no. 2, pp. 281-297, 2004.

[64] E. A. Miska, "How microRNAs control cell division, differentiation and death," Current Opinion in Genetics and Development, vol. 15, no. 5, pp. 563-568, 2005.

[65] E. E. Marsh, Z. Lin, P. Yin, M. Milad, D. Chakravarti, and S. E. Bulun, "Differential expression of microRNA species in human uterine leiomyoma versus normal myometrium," Fertility and Sterility, vol. 89, no. 6, pp. 1771-1776, 2008.

[66] C. Benassayag, M. J. Leroy, V. Rigourd et al., "Estrogen receptors $(\mathrm{ER} \alpha / \mathrm{ER} \beta)$ in normal and pathological growth of the human myometrium: pregnancy and leiomyoma," American Journal of Physiology, vol. 276, no. 6, pp. E1112-E1118, 1999.

[67] K. A. Kovács, A. Oszter, P. M. Göcze, J. L. Környei, and I. Szabó, "Comparative analysis of cyclin D1 and oestrogen receptor $(\alpha$ and $\beta$ ) levels in human leiomyoma and adjacent myometrium," Molecular Human Reproduction, vol. 7, no. 11, pp. 1085-1091, 2001.

[68] A. Olmos Grings, V. Lora, G. Dias Ferreira, I. Simoni Brum, H. Von Eye Corleta, and E. Capp, "Protein expression of estrogen receptors $\alpha$ and $\beta$ and aromatase in myometrium and uterine leiomyoma," Gynecologic and Obstetric Investigation, vol. 73, no. 2, pp. 113-117, 2012.

[69] H. Ishikawa, K. Ishi, V. Ann Serna, R. Kakazu, S. E. Bulun, and T. Kurita, "Progesterone is essential for maintenance and growth of uterine leiomyoma," Endocrinology, vol. 151, no. 6, pp. 24332442, 2010.

[70] H. Ishikawa, K. Ishi, V. Ann Serna, R. Kakazu, S. E. Bulun, and T. Kurita, "Progesterone is essential for maintenance and growth of uterine leiomyoma," Endocrinology, vol. 151, no. 6, pp. 2433$2442,2010$.

[71] A. Barbarisi, O. Petillo, A. Di Lieto et al., "17-beta estradiol elicits an autocrine leiomyoma cell proliferation: evidence for a stimulation of protein kinase-dependent pathway," Journal of Cellular Physiology, vol. 186, no. 3, pp. 414-424, 2001.

[72] P. Ciarmela, E. Bloise, P. C. Gray et al., "Activin-A and myostatin response and steroid regulation in human myometrium: disruption of their signalling in uterine fibroid," Journal of Clinical Endocrinology and Metabolism, vol. 96, no. 3, pp. 755-765, 2011.

[73] Y. Shimomura, H. Matsuo, T. Samoto, and T. Maruo, "Upregulation by progesterone of proliferating cell nuclear antigen and epidermal growth factor expression in human uterine leiomyoma," Journal of Clinical Endocrinology and Metabolism, vol. 83, no. 6, pp. 2192-2198, 1998.

[74] H. Matsuo, T. Maruo, and T. Samoto, "Increased expression of Bcl-2 protein in human uterine leiomyoma and its upregulation by progesterone," Journal of Clinical Endocrinology and Metabolism, vol. 82, no. 1, pp. 293-299, 1997.

[75] E. N. Nierth-Simpson, M. M. Martin, T. Chiang et al., "Human uterine smooth muscle and leiomyoma cells differ in their rapid 17/J-estradiol signaling: implications for proliferation," Endocrinology, vol. 150, no. 5, pp. 2436-2445, 2009. 
[76] S. Park, S. Ramachandran, S. Kwon et al., "Upregulation of ATP-sensitive potassium channels for estrogen-mediated cell proliferation in human uterine leiomyoma cells," Gynecological Endocrinology, vol. 24, no. 5, pp. 250-256, 2008.

[77] P. Kastner, A. Krust, B. Turcotte et al., "Two distinct estrogenregulated promoters generate transcripts encoding the two functionally different human progesterone receptor forms A and B," The EMBO Journal, vol. 9, no. 5, pp. 1603-1614, 1990.

[78] T. Maruo, N. Ohara, S. Yoshida et al., "Translational research with progesterone receptor modulator motivated by the use of levonorgestrel-releasing intrauterine system," Contraception, vol. 82, no. 5, pp. 435-441, 2010.

[79] J. J. Kim and E. C. Sefton, “The role of progesterone signaling in the pathogenesis of uterine leiomyoma," Molecular and Cellular Endocrinology, vol. 358, no. 2, pp. 223-231, 2011.

[80] O. Sadan, B. Van Iddekinge, and C. J. Van Gelderen, "Oestrogen and progesterone receptor concentrations in leiomyoma and normal myometrium," Annals of Clinical Biochemistry, vol. 24, no. 3, pp. 263-267, 1987.

[81] G. Marelli, A. M. Codegoni, and A. Bizzi, "Estrogen and progesterone receptors in leiomyomas and normal uterine tissues during reproductive life," Acta Europaea Fertilitatis, vol. 20, no. 1, pp. 19-22, 1989.

[82] D. D. Brandon, C. L. Bethea, E. Y. Strawn et al., "Progesterone receptor messenger ribonucleic acid and protein are overexpressed in human uterine leiomyomas," American Journal of Obstetrics and Gynecology, vol. 169, no. 1, pp. 78-85, 1993.

[83] B. Viville, D. S. Charnock-Jones, A. M. Sharkey, B. Wetzka, and S. K. Smith, "Distribution of the A and B forms of the progesterone receptor messenger ribonucleic acid and protein in uterine leiomyomata and adjacent myometrium," Human Reproduction, vol. 12, no. 4, pp. 815-822, 1997.

[84] Z. Ying and Z. Weiyuan, "Dual actions of progesterone on uterine leiomyoma correlate with the ratio of progesterone receptor A:B," Gynecological Endocrinology, vol. 25, no. 8, pp. 520-523, 2009.

[85] J. Fujimota, R. Hirose, S. Ichigo, H. Sakaguchi, Y. Li, and T. Tamaya, "Expression of progesterone receptor form A and B mRNAs in uterine leiomyoma," Tumor Biology, vol. 19, no. 2, pp. 126-131, 1998.

[86] A. Arici and I. Sozen, "Transforming growth factor- $\beta 3$ is expressed at high levels in leiomyoma where it stimulates fibronectin expression and cell proliferation," Fertility and Sterility, vol. 73, no. 5, pp. 1006-1011, 2000.

[87] O. Kurachi, H. Matsuo, T. Samoto, and T. Maruo, “Tumor necrosis factor- $\alpha$ expression in human uterine leiomyoma and its down-regulation by progesterone," Journal of Clinical Endocrinology and Metabolism, vol. 86, no. 5, pp. 2275-2280, 2001.

[88] P. Yin, Z. Lin, Y. Cheng et al., "Progesterone receptor regulates $\mathrm{Bcl}-2$ gene expression through direct binding to its promoter region in uterine leiomyoma cells," Journal of Clinical Endocrinology and Metabolism, vol. 92, no. 11, pp. 4459-4466, 2007.

[89] X. Luo, P. Yin, S. Reierstad et al., "Progesterone and mifepristone regulate L-type amino acid transporter 2 and 4F2 heavy chain expression in uterine leiomyoma cells," Journal of Clinical Endocrinology and Metabolism, vol. 94, no. 11, pp. 4533-4539, 2009.

[90] P. Yin, Z. Lin, S. Reierstad et al., "Transcription factor KLF11 integrates progesterone receptor signaling and proliferation in uterine leiomyoma cells," Cancer Research, vol. 70, no. 4, pp. 1722-1730, 2010.
[91] P. Ciarmela, M. S. Islam, F. M. Reis et al., "Growth factors and myometrium: biological effects in uterine fibroid and possible clinical implications," Human Reproduction Update, vol. 17, no. 6, Article ID dmr031, pp. 772-790, 2011.

[92] C. A. Anania, E. A. Stewart, B. J. Quade, J. A. Hill, and R. A. Nowak, "Expression of the fibroblast growth factor receptor in women with leiomyomas and abnormal uterine bleeding," Molecular Human Reproduction, vol. 3, no. 8, pp. 685-691, 1997.

[93] T. Hong, Y. Shimada, S. Uchida et al., "Expression of angiogenic factors and apoptotic factors in leiomyosarcoma and leiomyoma," International Journal of Molecular Medicine, vol. 8, no. 2, pp. 141-148, 2001.

[94] S. Arita, F. Kikkawa, H. Kajiyama et al., "Prognostic importance of vascular endothelial growth factor and its receptors in the uterine sarcoma," International Journal of Gynecological Cancer, vol. 15, no. 2, pp. 329-336, 2005.

[95] M. J. Rossi, N. Chegini, and B. J. Masterson, "Presence of epidermal growth factor, platelet-derived growth factor, and their receptors in human myometrial tissue and smooth muscle cells: their action in smooth muscle cells in vitro," Endocrinology, vol. 130, no. 3, pp. 1716-1727, 1992.

[96] Y. Ren, H. Yin, R. Tian et al., "Different effects of epidermal growth factor on smooth muscle cells derived from human myometrium and from leiomyoma," Fertility and Sterility, vol. 96, no. 4, pp. 1015.e1-1020.e1, 2011.

[97] Y. M. Fayed, J. C. M. Tsibris, P. W. Langenberg, and A. L. Robertson Jr., "Human uterine leiomyoma cells: binding and growth responses to epidermal growth factor, platelet-derived growth factor, and insulin," Laboratory Investigation, vol. 60, no. 1, pp. 30-37, 1989.

[98] A. Arici and I. Sozen, "Expression, menstrual cycle-dependent activation, and bimodal mitogenic effect of transforming growth factor- $\beta 1$ in human myometrium and leiomyoma," American Journal of Obstetrics and Gynecology, vol. 188, no. 1, pp. 76-83, 2003.

[99] M. Liang, H. Wang, Y. Zhang, S. Lu, and Z. Wang, "Expression and functional analysis of platelet-derived growth factor in uterine leiomyomata," Cancer Biology and Therapy, vol. 5, no. 1, pp. 28-33, 2006.

[100] G. Suo, Y. Jiang, B. Cowan, and J. Y. J. Wang, "Platelet-derived growth factor $\mathrm{C}$ is upregulated in human uterine fibroids and regulates uterine smooth muscle cell growth," Biology of Reproduction, vol. 81, no. 4, pp. 749-758, 2009.

[101] D. S. Joseph, M. Malik, S. Nurudeen, and W. H. Catherino, "Myometrial cells undergo fibrotic transformation under the influence of transforming growth factor $\beta-3$," Fertility and Sterility, vol. 93, no. 5, pp. 1500-1508, 2010.

[102] L. Ding, J. Xu, X. Luo, and N. Chegini, "Gonadotropin releasing hormone and transforming growth factor $\beta$ activate mitogenactivated protein kinase/extracellularly regulated kinase and differentially regulate fibronectin, type I collagen, and plasminogen activator inhibitor-1 expression in leiomyoma and myometrial smooth muscle cells," Journal of Clinical Endocrinology and Metabolism, vol. 89, no. 11, pp. 5549-5557, 2004.

[103] L. Yu, K. Saile, C. D. Swartz et al., "Differential expression of receptor tyrosine kinases (RTKs) and IGF-I pathway activation in human uterine leiomyomas," Molecular Medicine, vol. 14, no. 5-6, pp. 264-275, 2008.

[104] Z. Gao, H. Matsuo, Y. Wang, S. Nakago, and T. Maruo, "Upregulation by IGF-I of proliferating cell nuclear antigen and Bcl2 protein expression in human uterine leiomyoma cells," Journal 
of Clinical Endocrinology and Metabolism, vol. 86, no. 11, pp. 5593-5599, 2001.

[105] P. Ciarmela, E. Wiater, and W. Vale, "Activin-A in myometrium: characterization of the actions on myometrial cells," Endocrinology, vol. 149, no. 5, pp. 2506-2516, 2008.

[106] P. Ciarmela, E. Wiater, S. M. Smith, and W. Vale, "Presence, actions, and regulation of myostatin in rat uterus and myometrial cells," Endocrinology, vol. 150, no. 2, pp. 906-914, 2009.

[107] E. C. Weir, D. L. Goad, A. G. Daifotis, W. J. Burtis, B. E. Dreyer, and R. A. Nowak, "Relative overexpression of the parathyroid hormone-related protein gene in human leiomyomas," Journal of Clinical Endocrinology and Metabolism, vol. 78, no. 3, pp. 784789, 1994.

[108] M. Yoshida, A. Ohtsuru, T. Samejima et al., "Involvement of parathyroid hormone-related peptide in cell proliferation activity of human uterine leiomyomas," Endocrine Journal, vol. 46, no. 1, pp. 81-90, 1999.

[109] B. Gellersen, A. Bonhoff, N. Hunt, and H. G. Bohnet, "Decidualtype prolactin expression by the human myometrium," Endocrinology, vol. 129, no. 1, pp. 158-168, 1991.

[110] D. J. Austin, R. A. Nowak, and E. A. Stewart, "Onapristone suppresses prolactin production in explant cultures of leiomyoma," Gynecologic and Obstetric Investigation, vol. 47, no. 4, pp. 268271, 1999.

[111] F. Pekonen, T. Nyman, and E.-M. Rutanen, "Differential expression of mRNAs for endothelin-related proteins in human endometrium, myometrium and leiomyoma," Molecular and Cellular Endocrinology, vol. 103, no. 1-2, pp. 165-170, 1994.

[112] P. Robin, S. Chouayekh, C. Bole-Feysot, D. Leiber, and Z. Tanfin, "Contribution of phospholipase D in endothelin-1-mediated extracellular signal-regulated kinase activation and proliferation in rat uterine leiomyoma cells," Biology of Reproduction, vol. 72, no. 1, pp. 69-77, 2005.

[113] A. Horiuchi, T. Nikaido, T. Yoshizawa et al., "HCG promotes proliferation of uterine leiomyomal cells more strongly than that of myometrial smooth muscle cells in vitro," Molecular Human Reproduction, vol. 6, no. 6, pp. 523-528, 2000.

[114] S.-J. Tsai, S.-J. Lin, Y.-M. Cheng, H.-M. Chen, and L.-Y. C. Wing, "Erratum: Expression and functional analysis of pituitary tumor transforming growth factor-1 in uterine leiomyomas (The Journal of Clinical Endocrinology and Metabolism (2005) 90 (37153723))," Journal of Clinical Endocrinology and Metabolism, vol. 90, no. 9, p. 5233, 2005.

[115] M. Suzuki, S. Takamizawa, K. Nomaguchi et al., "Erythropoietin synthesis by tumour tissues in a patient with uterine myoma and erythrocytosis," British Journal of Haematology, vol. 113, no. 1, pp. 49-51, 2001.

[116] P. Hatthachote and J. I. Gillespie, "Complex interactions between sex steroids and cytokines in the human pregnant myometrium: evidence for an autocrine signaling system at term," Endocrinology, vol. 140, no. 6, pp. 2533-2540, 1999.

[117] K. V. Litovkin, V. P. Domenyuk, V. V. Bubnov, and V. N. Zaporozhan, "Interleukin-6-174G/C polymorphism in breast cancer and uterine leiomyoma patients: a population-based case control study," Experimental Oncology, vol. 29, no. 4, pp. 295298, 2007.

[118] T. L. Bonfield, J. R. Panuska, M. W. Konstan et al., "Inflammatory cytokines in cystic fibrosis lungs," American Journal of Respiratory and Critical Care Medicine, vol. 152, no. 6 I, pp. 21112118, 1995.
[119] B. Mehrad, M. P. Keane, and R. M. Strieter, "Chemokines as mediators of angiogenesis," Thrombosis and Haemostasis, vol. 97, no. 5, pp. 755-762, 2007.

[120] H. E. Broxmeyer, "Chemokines in hematopoiesis," Current Opinion in Hematology, vol. 15, no. 1, pp. 49-58, 2008.

[121] I. Sozen, D. L. Olive, and A. Arici, "Expression and hormonal regulation of monocyte chemotactic protein-1 in myometrium and leiomyomata," Fertility and Sterility, vol. 69, no. 6, pp. 1095$1102,1998$.

[122] L. M. Senturk, I. Sozen, L. Gutierrez, and A. Arici, "Interleukin 8 production and interleukin 8 receptor expression in human myometrium and leiomyoma," American Journal of Obstetrics and Gynecology, vol. 184, no. 4, pp. 559-566, 2001.

[123] S. F. Cramer, P. M. Newcomb, and T. A. Bonfiglio, "Myometrial dysplasia (atypical myometrial hyperplasia)," Human Pathology, vol. 38, no. 4, pp. 652-655, 2007.

[124] S. F. Cramer and A. L. Robertson Jr, "The origin of uterine leiomyomas," in The Extracellular Matrix of the Uterus, Cervix, and Fetal Membranes, P. C. Leppert and J. F. Woessner, Eds., pp. 213-223, Perinatology Press, Ithaca, NY, USA, 1991.

[125] M. Malik, J. Norian, D. McCarthy-Keith, J. Britten, and W. H. Catherino, "Why leiomyomas are called fibroids: the central role of extracellular matrix in symptomatic women," Seminars in Reproductive Medicine, vol. 28, no. 3, pp. 169-179, 2010.

[126] M. Wolańska, K. Sobolewski, M. Drozdzewicz, and E. Bańkowski, "Extracellular matrix components in uterine leiomyoma and their alteration during the tumour growth," Molecular and Cellular Biochemistry, vol. 189, no. 1-2, pp. 145-152, 1998.

[127] A. G. A. Berto, S. M. Oba, Y. M. Michelacci, and L. O. Sampaio, "Galactosaminoglycans from normal myometrium and leiomyoma," Brazilian Journal of Medical and Biological Research, vol. 34, no. 5, pp. 633-637, 2001.

[128] B. Bodner-Adler, K. Bodner, O. Kimberger, K. Czerwenka, S. Leodolter, and K. Mayerhofer, "Expression of matrix metalloproteinases in patients with uterine smooth muscle tumors: an immunohistochemical analysis of MMP-1 and MMP-2 protein expression in leiomyoma, uterine smooth muscle tumor of uncertain malignant potential, and leiomyosarcoma," Journal of the Society for Gynecologic Investigation, vol. 11, no. 3, pp. 182186, 2004.

[129] M. Bogusiewicz, M. Stryjecka-Zimmer, K. Postawski, A. J. Jakimiuk, and T. Rechberger, "Activity of matrix metalloproteinase- 2 and -9 and contents of their tissue inhibitors in uterine leiomyoma and corresponding myometrium," Gynecological Endocrinology, vol. 23, no. 9, pp. 541-546, 2007.

[130] H. Hricak, C. Alpers, L. E. Crooks, and P. E. Sheldon, "Magnetic resonance imaging of the female pelvis: initial experience," American Journal of Roentgenology, vol. 141, no. 6, pp. 1119-1128, 1983.

[131] A. Tocci, E. Greco, and F. M. Ubaldi, "Adenomyosis and endometrial-subendometrial myometrium unit disruption disease are two different entities," Reproductive BioMedicine Online, vol. 17, no. 2, pp. 285-291, 2008.

[132] J. J. Brosens, F. G. Barker, and N. M. DeSouza, "Myometrial zonal differentiation and uterine junctional zone hyperplasia in the non-pregnant uterus," Human Reproduction Update, vol. 4, no. 5, pp. 496-502, 1998.

[133] Practice Committee of the American Society for Reproductive Medicine, "Myomas and reproductive function," Fertility and Sterility, vol. 82, 1, pp. S111-S116, 2004. 
[134] V. C. Buttram Jr. and R. C. Reiter, "Uterine leiomyomata: etiology, symptomatology, and management," Fertility and Sterility, vol. 36, no. 4, pp. 433-445, 1981.

[135] J. M. Berman, "Intrauterine adhesions," Seminars in Reproductive Medicine, vol. 26, no. 4, pp. 349-355, 2008.

[136] C. Davies, M. Gibson, E. M. Holt, and E. P. H. Torrie, "Amenorrhoea secondary to endometrial ablation and Asherman's syndrome following uterine artery embolization," Clinical Radiology, vol. 57, no. 4, pp. 317-318, 2002.

[137] A. A. Hare and K. S. Olah, "Pregnancy following endometrial ablation: a review article," Journal of Obstetrics and Gynaecology, vol. 25, no. 2, pp. 108-114, 2005.

[138] A. Magos, "Hysteroscopic treatment of Asherman's syndrome," Reproductive BioMedicine Online, vol. 4, 3, pp. 46-51, 2002.

[139] S. F. Cramer, L. Mann, E. Calianese, J. Daley, and K. Williamson, "Association of seedling myomas with myometrial hyperplasia," Human Pathology, vol. 40, no. 2, pp. 218-225, 2009.

[140] L. M. Scoutt, S. D. Flynn, D. J. Luthringer, T. R. McCauley, and S. M. McCarthy, "Junctional zone of the uterus: correlation of MR imaging and histologic examination of hysterectomy specimens," Radiology, vol. 179, no. 2, pp. 403-407, 1991.

[141] C. Bulletti, D. De Ziegler, V. Polli, and C. Flamigni, "The role of leiomyomas in infertility," Journal of the American Association of Gynecologic Laparoscopists, vol. 6, no. 4, pp. 441-445, 1999.

[142] P. A. Richards, P. D. G. Richards, and A. J. Tiltman, "The ultrastructure of fibromyomatous myometrium and its relationship to infertility," Human Reproduction Update, vol. 4, no. 5, pp. 520-525, 1998.

[143] O. Yoshino, T. Hayashi, Y. Osuga et al., "Decreased pregnancy rate is linked to abnormal uterine peristalsis caused by intramural fibroids," Human Reproduction, vol. 25, no. 10, pp. 24752479, 2010.

[144] T. Inoue, H. Kanzaki, M. Iwai et al., "Tumour necrosis factor $\alpha$ inhibits in-vitro decidualization of human endometrial stromal cells," Human Reproduction, vol. 9, no. 12, pp. 2411-2417, 1994.

[145] M. Kariya, H. Kanzaki, K. Takakura et al., "Interleukin-1 inhibits in Vitro decidualization of human endometrial stromal cells," Journal of Clinical Endocrinology and Metabolism, vol. 73, no. 6, pp. 1170-1174, 1991.

[146] N. Inagaki, L. Ung, T. Otani, D. Wilkinson, and A. Lopata, "Uterine cavity matrix metalloproteinases and cytokines in patients with leiomyoma, adenomyosis or endometrial polyp," European Journal of Obstetrics Gynecology and Reproductive Biology, vol. 111, no. 2, pp. 197-203, 2003.

[147] S. Matsuzaki, M. Canis, C. Darcha, J. Pouly, and G. Mage, "HOXA-10 expression in the mid-secretory endometrium of infertile patients with either endometriosis, uterine fibromas or unexplained infertility," Human Reproduction, vol. 24, no. 12, pp. 3180-3187, 2009.

[148] B. C. Paria, J. Reese, S. K. Das, and S. K. Dey, "Deciphering the cross-talk of implantation: advances and challenges," Science, vol. 296, no. 5576, pp. 2185-2188, 2002.

[149] B. W. Rackow and H. S. Taylor, "Submucosal uterine leiomyomas have a global effect on molecular determinants of endometrial receptivity," Fertility and Sterility, vol. 93, no. 6, pp. 2027-2034, 2010.

[150] D. C. Sinclair, A. Mastroyannis, and H. S. Taylor, "Leiomyoma simultaneously impair endometrial BMP-2-mediated decidualization and anticoagulant expression through secretion of TGFB3," Journal of Clinical Endocrinology and Metabolism, vol. 96, no. 2, pp. 412-421, 2011.
[151] K. Y. Lee, J. Jeong, J. Wang et al., "Bmp2 is critical for the murine uterine decidual response," Molecular and Cellular Biology, vol. 27, no. 15, pp. 5468-5478, 2007.

[152] E. B. Morosova, A. B. Chukhlovin, N. V. Kulagina, N. V. Kipich, and A. A. Totolian, "Functional gene polymorphism of matrix metalloproteinase-1 is associated with benign hyperplasia of myo- and endometrium in the Russian population," Genetic Testing and Molecular Biomarkers, vol. 16, no. 9, pp. 1032-1037, 2012. 


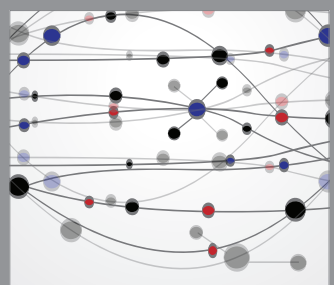

The Scientific World Journal
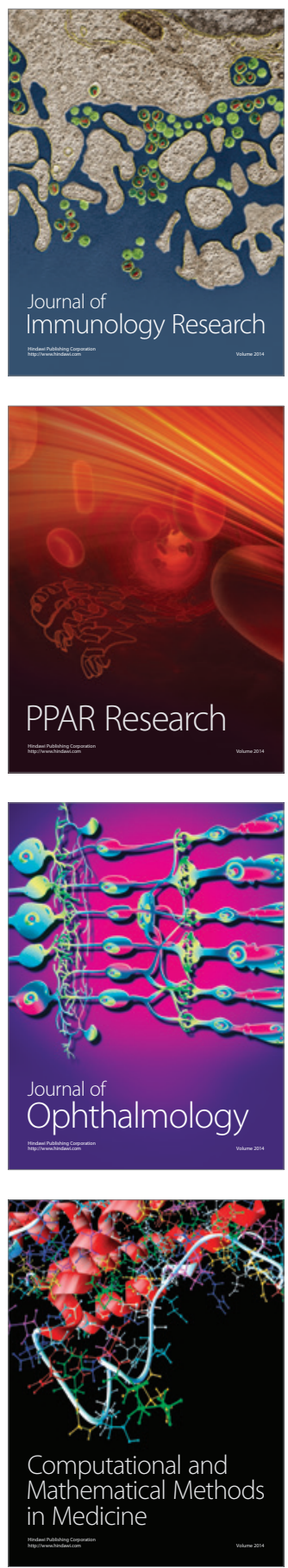

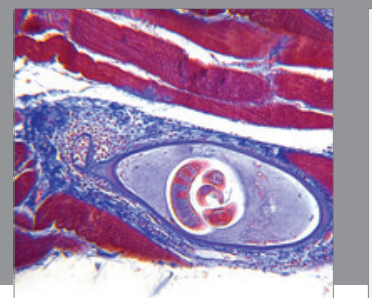

Gastroenterology

Research and Practice
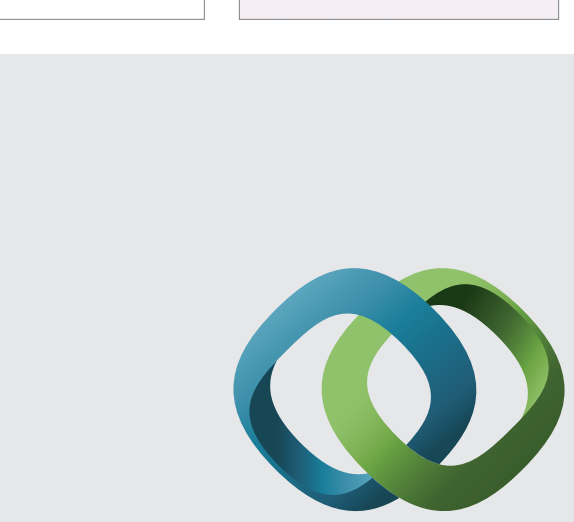

\section{Hindawi}

Submit your manuscripts at

http://www.hindawi.com
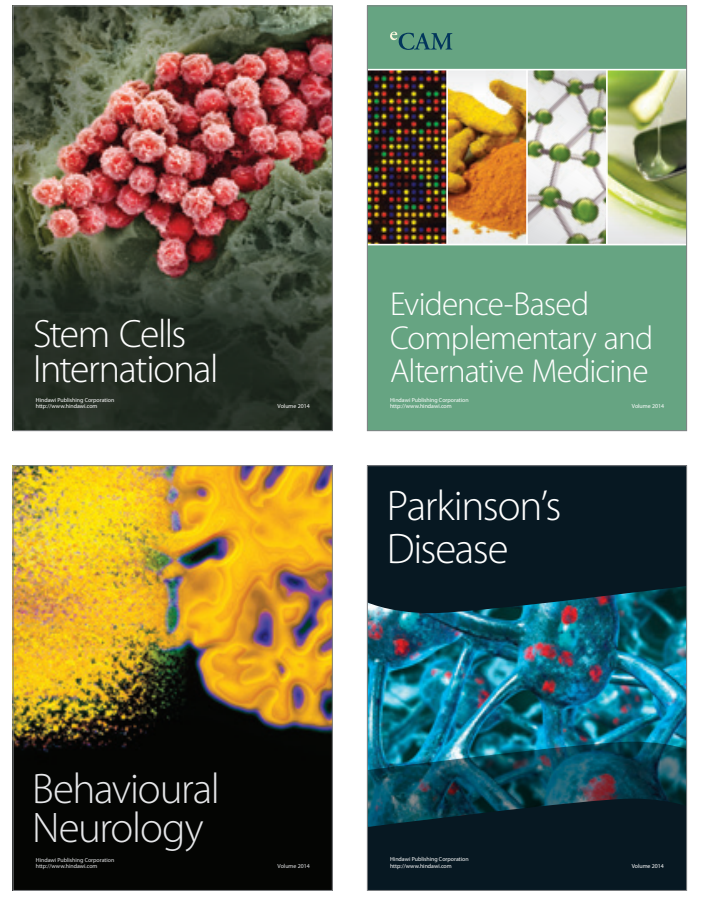
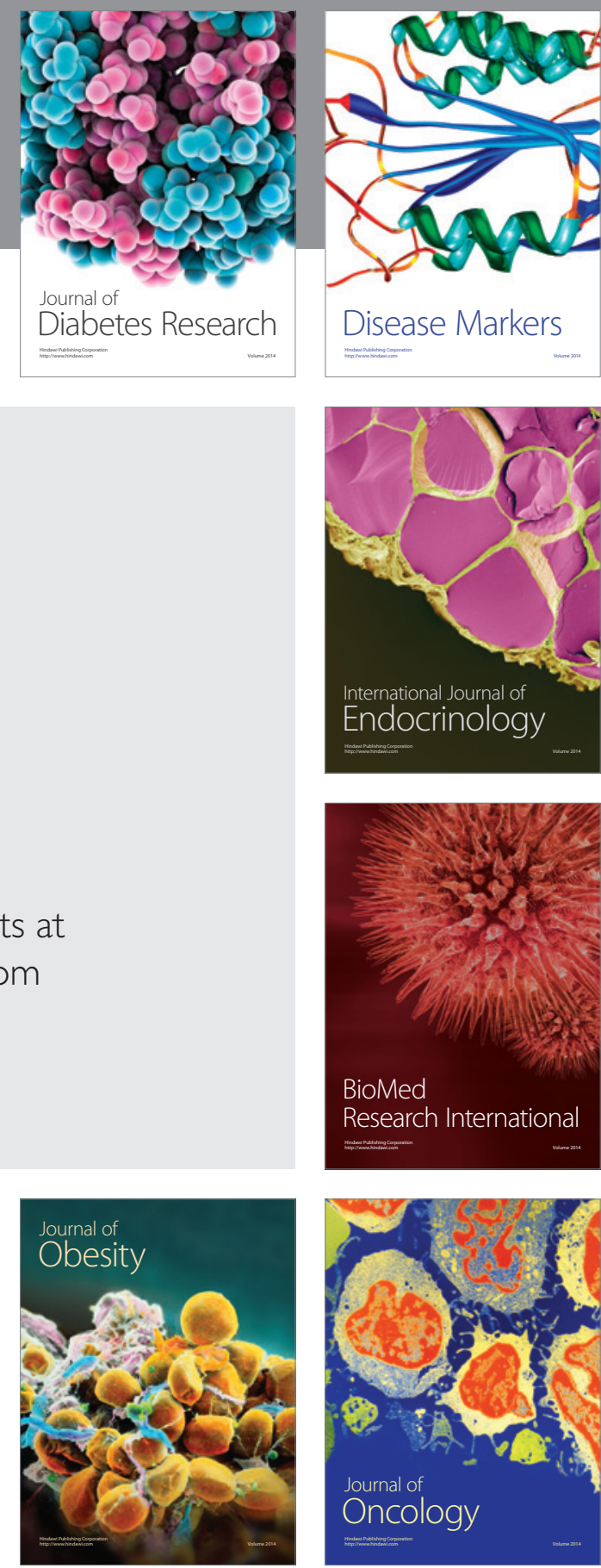

Disease Markers
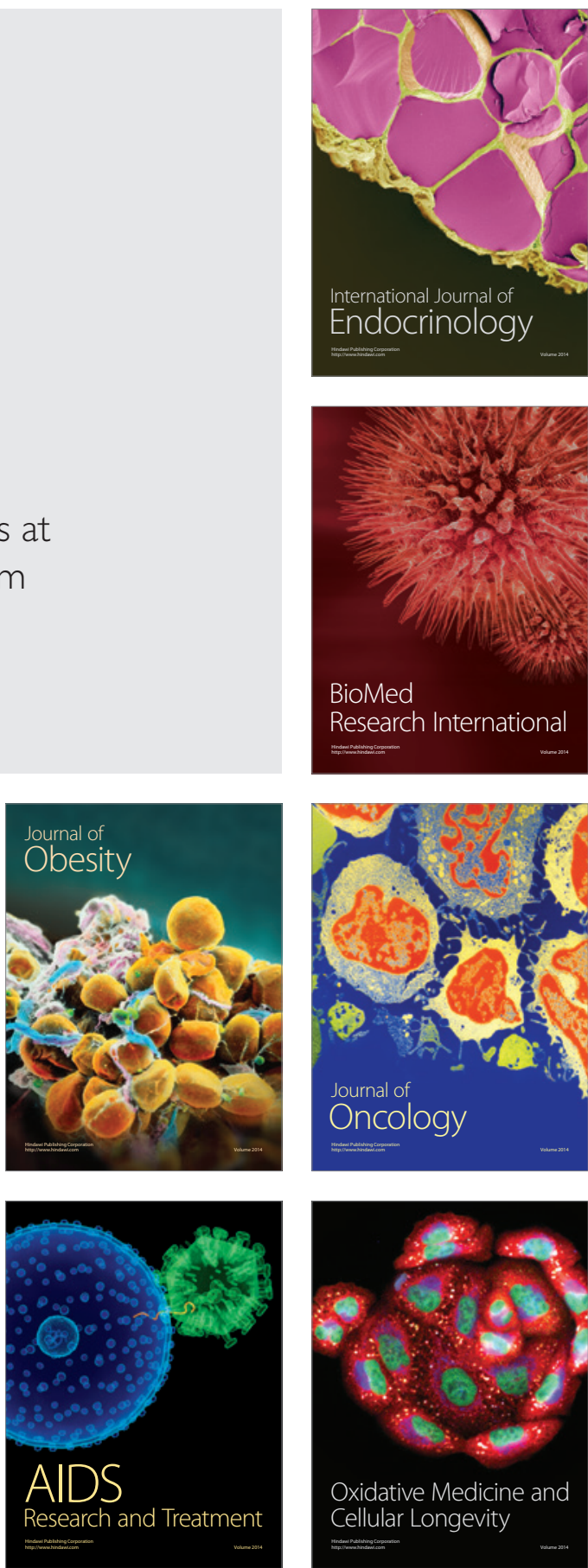